\title{
The Effect of Multimodal Learning Models on Language Teaching and Learning
}

\author{
Abbas Pourhossein Gilakjani \\ School of Educational Studies, Universiti Sains Malaysia, Malaysia \\ Email: abbas.pourhossein@yahoo.com \\ Hairul Nizam Ismail \\ School of Educational Studies, Universiti Sains Malaysia, Malaysia \\ Email: hairul@usm.my \\ Seyedeh Masoumeh Ahmadi \\ School of Computer, Universiti Sains Malaysia, Malaysia \\ Email:s_m_a57@yahoo.com
}

\begin{abstract}
When we talk about multimedia learning, we can ask several questions to ourselves understand the effect of information and communication technologies (ICT's) on our lives. ICT's have introduced new instructions that we use to think; consequently, the ways in which we think would also change. New identities are born that are connected to communication tools. From the viewpoint of applied linguistics, we are specifically interested in the effects that these communicative skills can have on the processes of language production and interpretation. Our conceptions of language and communication have changed substantially with the arrival of computer and its digital capabilities. Communications have also changed considerably. These changes have affected the school communities and the relationships established between teachers and students now involve other modes of cognitive involvement and social interactions made possible by digital online communications. In this paper, the researchers discuss the issues of ICT, multimedia learning, its principles, CALL, its advantages and implications of multimedia learning. Then multimodal learning, multimodality and second language acquisition, and implications of multimodality in language learning and teaching will be discussed. A review of the literature will determine how multimodal models affect the teaching and learning processes.
\end{abstract}

Index Terms-multimedia learning, communication, ICT's, CALL, production, interpretation, representation

\section{INTRODUCTION}

When we talk about multimedia learning, several questions occur in our minds concerning the impact of information and communications technology (ICT) on our lives. Information and communication technology (ICT) provides academics with an opportunity to create rich learning environments for their students, enhanced by the wealth of information and resources on the Internet, as well as the inclusion of a range of multimedia-based learning elements. Multimodal courses involve the use of multimedia and ICT to develop dynamic course resources that appeal to different sensory modes and a variety of learning styles (Sankey \& Birch, 2005). For example, a multimodal course may include elements such as simulations, interactive diagrams, images, video and audio materials, interactive quizzes and crosswords, PowerPoint lectures with audio, and hyperlinked examples. With this new flexibility, major concepts within course material may be presented in a variety of modes (multiple representations), for example, in both a visual and aural form. This strategy leads learners to perceive that it is easier to learn, improve attention rates, and improve learning performance. There are marked differences in both computer skills and cognitive skills among learners that these technologies are bringing about. ICT have introduced new tools that we use to think; consequently, the ways in which we think would also change (Sankey, 2006).

We are specifically interested in the impacts of these technologies on the processes of language production and interpretation. Our conceptions of language and communication have changed substantially with the arrival of the computer and its digital capabilities. Communications have also changed considerably. These changes have had an important influence on the learning environment. In this paper, the authors discuss the issue of ICT, multimedia learning, its principles, CALL, its advantages and implications of multimedia learning. Then, multimodal learning, multimodality and second language acquisition, and implications of multimodality in language learning and teaching will be discussed.

\section{INFORMATION AND COMMUNICATION TECHNOLOGY (ICT) IN SCIENCE EDUCATION}


Since science can be viewed as contents, e.g. the laws, theories, facts, and as processes, e.g. measuring, recording, processing data, information and communication technology (ICT) in science education aims to support both (Wellington, 2000). Simulations and modelling offer a wide range of opportunities by either describing reality or simplifying it to aid conceptual interpretation. Simulations refer to models that are created by others; modelling refers to models that are created by pupils. Simulations show phenomena and processes that might be too slow or fast to do in the school lab; they offer access to non-existing entities, they model activities that would be dangerous or expensive to carry out by pupils (Wellington, 2000). Through simulations, variable can be controlled and teachers can focus on theoretical issues instead of dealing with managing the lab. Simulations are not panacea for learning science: easy manipulation of variables may lead to misunderstanding that happens in reality, models are hidden from the pupils which cause them to be able to manipulate only factors within this model and cannot question the model. So they may confuse the model with reality. Some models are better than others and some models are caricatures of reality rather than representations of it (Wellington, 2000). It is the teacher who can safeguard such confusions by stressing the fact that simulations are models and emphasize their limitations. ICT systems are useful for collecting and storing large amount of data, performing complex calculations on stored data, processing large amounts of data and displaying them in a variety of formats, helping to present and communicate information. Computers can be used for a variety of reasons to interact with multimedia software, to browse the Internet, to log data. However, the use of ICT in schools has shown weaknesses: the objectives are sometimes unclear, there are low expectations of written outcomes, glossy computergenerated effects are accepted without extending pupils' abilities, allowing students to reproduce information rather than analyse it (Wellington, 2000).

\section{LEARNING WITH MULTIMEDIA}

Multimedia has been successfully applied to many courses in order to provide a wide variety of learning styles or modalities (Birch \& Gardiner, 2005). Learning styles are defined as characteristic cognitive, affective, and physiological behaviours that serve as relatively stable indicators of how learners perceive, interact with, and respond to the learning environment. Learners are more comfortable learning in an environment which reflects their predominant learning style (Sankey, 2006). Learners have a preferred learning modality, namely, visual, aural, read/write or kinaesthetic, while many learners are multimodal (use a combination of these modalities). Multimedia can be used to develop a more inclusive curriculum that appeals to visual, aural and kinaesthetic learners and overcome differences in student performance that may result from different learning styles. Presenting material in a variety of modes has been used to encourage students to develop a more versatile approach to learning (Morrison, Sweeney, \& Heffernan, 2003).

Moving from the book to the computer is the opportunity for greater interactivity and novel ways to think about a learning activity. Technology provides more ways to represent concepts through different media formats. Such advances in technology ask for pedagogical enquiries to confirm the usefulness of such new activities in facilitating learning. Learners who have access to multiple representations enhance their comprehension, learning, memory, communication and inference (Scaife \& Rogers, 1996). Kozma (1991) argues that learners will benefit more if the instructional methods provide, perform or model cognitive operations that are important to the task and the situation. Learners will benefit more if they can perform or provide for themselves the operations provided by these representational media (Kozma, 1991). Providing the learner with a sound structure and content is more important than providing them with interactivity and animation afforded by new media. Comprehension and learning require a sound content and structure of instructional material, and not new media or types of representation. The combination of text and image is effective when the information provided is complementary and adapted to each presentation. Making connections from multiple representations depend not only on the presentation mode and the construction of the interrelations between the multimodal items but also on the characteristics of the task (Dubois \& Vial, 2000).

\section{PRINCIPLES OF MULTIMEDiA}

We identify some of the most important principles of multimedia learning and what the research says about how they contribute to student learning.

\section{A. Words and Pictures are Better than Words Alone.}

People learn better from words and pictures than from words alone (Mayer, 2005). Words include written and spoken text, and pictures include static graphic images, animation and video. The use of both words and pictures lets the brain processes more information in working memory (Sweller, 2005). Mayer (2005) tells us that narration and video is much more effective than narration and text. Similarly, narration and video appear to be more effective than narration, video and text. Narration and text rely on the same channel to process information.

\section{B. Multimedia Learning is more Effective When Learner Attention is Focused, not Split.}

Multimedia applications are more effective when learner's attention is not split. Split attention occurs when the learner is forced to attend to information that is far apart, such as when content is visually far apart on the screen or if it is presented at two separate points in time. When related content is presented together in time visually, learning is more effective (Mayer, 2005). When related content is not presented together, learner attention is split and the brain has more 
work to do to integrate the disparate sources of information. Words and pictures presented simultaneously are more effective than when presented sequentially (Mayer \& Sims, 1994).

\section{The Presentation of Multimedia Content Should Exclude Extraneous and Redundant Information.}

Multimedia learning is most effective when it includes only content that is relevant and aligned to the instructional objectives (Mayer, 2003). Kalyuga, Chandler and Sweller (1999) found that students learned more when extraneous and redundant information was not included in a multimedia presentation. Learning is most effective when interesting and irrelevant information is eliminated because of the brain's limited information processing resources.

\section{Multimedia Learning is more Effective When it is Interactive and under the Control of the Learner.}

Not all students learn at the same pace. Research tells us that when learners are able to control the pace of the presentation they learn more. Multimedia presentations are more effective when the learner has the ability to interact with the presentation, by slowing it down or by starting and stopping it. This pacing can also be achieved by breaking the presentation into segments; shorter segments that allow users to select segments at their own pace work better than longer segments that offer less control (Mayer, 2003).

\section{E. Multimedia Learning is more Effective When Learner Knowledge Structures are Activated prior to Exposure to Multimedia Content.}

Learning from multimedia presentations is enhanced when the structures for organizing the information are activated (Pollock, Chandler, \& Sweller, 2002). Helping students recall or acquire structures that will help them organize and understand the information can be accomplished in several ways. Activation can be accomplished by allowing students to preview the content through demonstrations, discussion, directed recall and written descriptions. These preview activities should be directed at activating prior knowledge (Kalyuga, 2005), signalling what is important, and showing how the content is organized. Activating knowledge helps provide a structure from long term memory to understand and organize the new information from working memory.

\section{F. Multimedia Instruction that Includes Animation can Improve Learning.}

When used effectively, animated content can improve learning. Animation appears to be most effective when presenting concepts or information that students may have difficulty envisioning. Animation is more effective when students have the ability to start and stop the animation and view it at their own pace or are able to manipulate various facets of the animation. Animation is more effective if it is accompanied by narration, which makes use of both the auditory and visual channels (Mayer \& Chandler, 2001).

\section{G. Multimedia Leaning is most Effective When the Learner is Engaged with the Presentation.}

Multimedia is most effective when the content and format actively engage the learner. Active engagement helps the student construct knowledge and organize information into meaningful schema (Mayer, 2003). Multimedia that is more personalized engages learners more than multimedia that is less personalized (Mayer, 2005). Presentations that have a more conversational tone tend to be more engaging than those that have a more formal tone. Presentations that use the more familiar -you and I- are more engaging than those that present in the third person (Mayer, 2005). Learners tend to find presentations that use a familiar voice with a familiar accent more engaging than those that use a less familiar voice and accent (Mayer, Sobko \& Mautone, 2003).

\section{H. Multimedia Learning is most Effective when the Learner can Apply their Newly Acquired Knowledge and Receive Feedback.}

Multimedia is most likely to be effective when students are provided with opportunities to apply what they have learned following exposure (Mayer, 2005). This reinforces and strengthens the newly acquired knowledge. Students should be provided with opportunities to integrate what they have learned with their everyday life. Feedback is an important part of the learning process. It is important to provide learners with clear feedback about their progress on an ongoing basis (Gee, 2005). Feedback helps keep students informed about their progress and helps them stay engaged. Providing feedback can reinforce what has been learned and can also correct any misconceptions (Gee, 2005).

\section{COMPUter Assisted LANGUAGe LeARning (CALL)}

Computer-assisted language learning (CALL) is a form of computer-based learning which carries two important features: individualized learning and bidirectional learning. CALL materials are materials for learning. The focus of CALL is learning, and not teaching. CALL materials are used in teaching to facilitate the language learning process. It is a form of student-centred learning materials, which promote self-paced accelerated learning. CALL is not a software application, but rather courseware that is designed for language learning for a specific group of learners. The philosophy of CALL puts a strong emphasis on student-centred lessons that allow the learners to learn on their own using structured and/or unstructured interactive lessons. These lessons carry 2 important features: bidirectional (interactive) learning and individualized learning. It is a tool that helps teachers to facilitate language learning process. CALL can be used to reinforce what has been learned in the classrooms. It can also be used as remedial to help learners with limited language 
proficiency (Warschauer, 2008). The reasons for using Computer-assisted Language Learning include: (a) experiential learning, (b) motivation, (c) enhance student achievement, (d) authentic materials for study, (e) greater interaction, (f) individualization, $(\mathrm{g})$ independence from a single source of information, and $(\mathrm{h})$ global understanding (Warschauer, 2008).

\section{Advantages of COMPUter Assisted LANGUAGE LEARNing (CALL)}

Some researchers indicate that the current computer technology has many advantages for second language learning. Computer and its attached language learning programs could provide second language learners more independence from classrooms and allowing learners the option to work on their learning material at any time of the day. Once implemented, it can be expected that the cost for computer technology is considerably lower than for face-to-face classroom teaching, and when used in conjunction with traditional second language classroom study, students can study more independently, leaving the teacher more time to concentrate effort on those parts of second language teaching that are still hard or impossible by the computer, such as pronunciation, work on spoken dialogue, training for essay writing and presentation(Jonassen, 1996; Salaberry, 1999).

The reasons why we should apply computer technology in second language instruction, include computer and its attached language learning programs can (a) prove practices for students through the experiential learning, (b) offer students more the learning motivation, (c) enhance student achievement, (d) increase authentic materials for study, (e) encourage greater interaction between teachers and students and students and peers, (f) emphasize the individual needs, (g) regard independence from a single source of information, and (h) enlarge global understanding (Lee, 2000). Taylor (1980) also expressed that computer assisted language learning programs can be wonderful stimuli for second language learning. Currently, computer technology can provide a lot of fun games and communicative activities, reduce the learning stresses and anxieties, and provide repeated lessons as often as necessary. Those abilities will promote second language learners' learning motivation. Through various communicative and interactive activities, computer technology can help second language learners strengthen their linguistic skills, affect their learning attitude, and build their selfinstruction strategies and self-confidence.

With the high development of computer technology, computers can capture, analyze, and present data on second language students' performances during the learning process. Observing and checking students' learning progress are very important activities to help students achieve their second language acquisition. When teachers attempt to assess students' learning progress, they can get the essential information from a well-designed computer language learning programs and then offer feedback tailored to students' learning needs (Taylor \& Gitsaki, 2003). In addition, Students can get various authentic reading materials either at school or from home by connecting to the Internet. And, those materials can be accessed 24 hours a day. In a word, computer technology also provides the interdisciplinary and multicultural learning opportunities for students to carry out their independent studies (Taylor \& Gitsaki, 2003).

Warchauer (2004) indicated that the random access to Web pages would break the linear flow of instruction. By sending E-mail and joining newsgroups, second language learners can also communicate with people they never met before and interact with their own teachers or classmates. Shy or inhibited learners can be greatly benefited through the individualized technology-learning environment, and studious learners can also proceed at their own pace to achieve higher levels. Many concepts and cognitions are abstract and difficult to express through language the language teaching area. It seems that computers can make up for this shortage by using the image showing on the screen. Nunan (1999) reported that "interactive visual media which computers provided seem to have a unique instructional capability for topics that involve social situations or problem solving, such as interpersonal solving, foreign language or second language learning" (p. 26).

When computer technology combines with Internet, it creates a channel for students to obtain a huge amount of human experience and guide students to enter the "Global Community". In this way, students not only can extend their personal view, thought, and experience, but also can learning to live in the real world. They become the creators not just the receivers of knowledge. And, "as the way information is presented is not linear, second language learners can still develop thinking skills and choose what to explore" (Lee, 2000).

\section{IMPLICATIONS OF MULTIMEDIA IN LEARNING}

Multimedia are resources that make effective use of computer technology by providing simulations, multiple representations, and informative and immediate feedback to learner's actions at the interface. While interacting with well-constructed multimedia programs, learners can explore the learning environment in their own time, and at their own pace. Multimedia applications for learning purposes accommodate verbal and visual representations with the use of dynamic or static information (Stoney \& Oliver, 1999). Learning environments that provide learners with multiple representations offer opportunities for greater interactivity, and complementarity. There are implications about the importance of interactivity (Healey et al., 2002), and complementarity (Ainsworth, 1999) in the literature and some of them are analyzed below. Animations and virtual environments can emphasize the key-components of the phenomena under study, highlight the underlying processes explicitly and provide feedback to learners' actions (Scaife \& Rogers, 1996). Interactivity has been defined as a facility by which a user acts on a computer presentation which in turn 
interprets the user's action and produces the appropriate response. Interactivity gives learners the opportunity to reinspect and facilitate their perception and comprehension through zooming, controlling of speed and viewing alternative perspectives (Tversky et al., 2002). However, learners still need to learn to 'read' the content of the animations in relation to the information presented verbally or as text and to assimilate it with their current understanding of the domain (Scaife \& Rogers, 1996). Complementarity refers to the ability to present information or a structure in multiple equivalent ways. Thus, it can refer to both complementary processes and complementary information. When there is complex information to be shown or when there is no single representation that would sufficiently carry all the necessary content, multiple representations can be useful (Ainsworth, 1999). When employing multiple representations, learners can benefit from the different complementary processes that each representation supports: they can use more than one strategy and have the chance to exhibit preferences (Ainsworth, 1999).

\section{MULTIMODAL LEARNING}

Multiple representations provide some advantages for learners to learn. Studying the importance of multiple representations shows an overriding focus on "visualizing to be recognized". Viewing multiple ways of presenting concepts stresses the importance of vision in understanding, ignoring the effects of other senses in a learning activity. Learning is not only a visual-cognitive activity but also a physical one particularly as it requires the interplay among multiple sensory modalities and representations. The literature is mainly talking about visual and linguistic representations which are beneficial for specific tasks but they might not be appropriate for the whole spectrum of the learning activities. Learning is closely related to experiencing life and in life we employ all of our senses -not just vision. For learners to be engaged into a subject, they need to relate themselves and connect their everyday life to the learning material; in other words, they need to be situated. Such relationships could be generated by following an alternative approach to learning: one that incorporates learners' multiple modalities and the available instruments of the environment including the multiple representations provided by books or multimedia software. Such an approach is argued to be multimodal learning (Daniels, 2001).

\section{Multimodality AND SECOND LANGUAGE ACQuisition}

Firth and Wagner (2003) contend that our ultimate goal is to argue for a re-conceptualization of SLA as a more theoretically and methodologically balanced enterprise that endeavors to attend to, explicate, and explore both the social and cognitive dimensions of S/FL use and acquisition. They argue that researchers will be better able to understand and explicate how language is used as it is being acquired through interaction resourcefully, contingently, and contextually. Language is not only a cognitive phenomenon, the product of the individual's brain; it is also fundamentally a social phenomenon, acquired and used interactively, in a variety of contexts for myriad practical purposes. Multimedia presentations can be an excellent means toward "re-constructing" a pseudo-natural environment in which these negotiations of meaning that serve as the platform for second language acquisition can take place. Accompanying the interaction between teacher and second language learners with a combination of modes such as animation (visuals and movement) and narration can provide a variety of contexts to be used for developing all the components of communicative competence. Mayer and Sims (1994) apply the concept of multimedia to the teacher's presentation of information through more than one medium and the concept of "multimodality" to the learner's use of more than one sense. They state that: Multimedia learning occurs when students use information presented in two or more formats such as a visually presented animation and verbally presented narration- to construct knowledge. Our definition applies to the term "multimodal" (which refers to the idea that the learner uses more than one sense modality) rather than "multimedia" (which refers to the idea that the instructor uses more than one presentation medium).

\section{IMPLICATIONS OF MULTIMODALITY IN LANGUAGE LEARNING AND TEACHING}

A multimodal approach to the classroom highlights the important use of multiple modalities in real learning environments. Children select or negotiate the meanings conveyed from modalities to construct conceptions about the world. Each modality contains information that is a resource for pupil's meaning construction. Each modality covers a different aspect of phenomena which could challenge prior conceptions of the world and provide resources to imagine and think with (Kress et al., 2001). According to Kress et al., (2001), teachers often use gestures together with speech to draw attention to images and other references within the classroom. In particular, they argue: a variety of modes are interacting and interplaying: gestures, drawings, speech, objects. Each mode contributes to meaning construction: speech to create a difference, an image on the blackboard to get a visual backdrop, manipulation of an object to locate the discussion in the physical setting, action to make clear the dynamic nature of the concept, the image in the textbook to do a stable summary, cohesion is achieved through repetition, synchronization, similarity and contrast. The selection of modes makes meaning: the metaphorical path will be different in each case. Each mode plays a different role in the construction of the entity at hand. Each mode requires the pupils to do a different type of work in order to understand (Kress et al., 2001).

Moreno and Mayer (2007) believe that multimodal learning environments use different modes to represent content knowledge, for example verbal and non-verbal, where the non-verbal mode is the pictorial mode including both static 
and dynamic graphics. These different presentation modes (verbal and non-verbal) are used to appeal to students' different sensory modalities (visual and auditory). Further, Multimodal courses allow instructional events or elements to be presented in more than one sensory mode (multiple representations), thus have been used to further facilitate student's learning (Shah \& Freedman, 2003). The development of technology enhanced courses may result in a more current and relevant curriculum, innovation and new ideas, enhanced course quality, and diversification of academic programs (Maguire, 2005). ICT has significantly changed the way that teaching, learning and assessment occur. For example, the adoption and integration of ICT may lead to more student-centered approaches to teaching and learning, and thus support a more constructivist approach to course design. This is primarily due to the non-linear design of learning environments that has been found to increase learners' control over the way they progress through their materials (Karagiorgi \& Symeou, 2005).

\section{CONCLUSION}

Multimedia presentations compensate for absence of appropriate cognitive structures in certain domains due to the lack of opportunities that characterize certain communities and social groups- and also compensate for the weak or incomplete development of verbal skills. The research agenda calls for studies to evaluate the principles of multimodal learning and the electronic multimedia designs as they affect the acquisition of reading, writing, speaking and listening in various EFL contexts. A multidisciplinary approach is needed to understand the social, cognitive, cultural and linguistic variables involved in the process of language learning. Questions like the following can guide such agenda: what types of multimedia designs are more helpful for learners with different learning styles? What is the impact of the audio, linguistic, visual, gestural and spatial meaning making dimensions in the learning process? Can teachers offer learners opportunities to select the processing mode that best fits their learning style? The lines of research reviewed here can set the grounds for empirical investigations into the various arrangements and affordances that multimodality offers for the process of language learning. The quick pace of change from print-based to more visually oriented presentations of information involves a quick response from language teachers and educators to take advantage of multimodality to engage learners in meaningful cognitive, critical understandings. Attention to the meaning-making potential of the various multimodal designs can help language learners to cope more efficiently as they face new modes of information presentation.

\section{REFERENCES}

[1] Ainsworth, S. (1999). The functions of multiple representations. Computers and Education, 33, 131-152.

[2] Birch, D., \& Gardiner, M. (2005). Students' perceptions of technology-based marketing courses. Proceedings of Australia and New Zealand Marketing Educators Conference, December, 5-7, Fremantle, Australia.

[3] Daniels, H. (2001). Vygotsky and Pedagogy. London: Routledge.

[4] Dubois, M., \& Vial, I. (2000). Multimedia design: The effects of relating multimodal information. Journal of Computer Assisted Learning 16, 157-165.

[5] Firth, A., \& Wagner, J. (2003). On discourse, communication, and (some) fundamental Concepts in SLA Research (Text 20), Section on SLA. In Seidlhofer, B. (Ed.), Controversies in applied linguistics (pp.173-198). New York: CUP.

[6] Gee, J. P. (2005). Learning by design: Good video games as learning machines, E-Learning, (2), 5-16.

[7] Healey, P., Narayanan, N. H., Lee, J., \& Katagiri, Y. (2002). Introduction: interactive graphical communication. International Journal of Human Computer studies, 57 (4), 243-246.

[8] Jonassen, D. H. (1996). Computers in the classroom. Englewood cliffs, NJ: Merrill.

[9] Kalyuga, S. (2005). Prior knowledge principle in multimedia learning. In R. E. Mayer (Ed.). The Cambridge Handbook of Multimedia Learning. New York: Cambridge University Press.

[10] Kalyuga, S., Chandler, P. \& Sweller, J. (1999). Managing split attention and redundancy in multimedia instruction. Applied Cognitive Psychology, 13, 351-371.

[11] Karagiorgi, Y., \& Symeou, L. (2005). Translating constructivism into instructional design: Potential and limitations. Educational Technology \& Society, 8 (1), 17-27.

[12] Kozma, R. B. (1991). Learning with media. Review of Educational Research, 61, 179-211.

[13] Kress, G. R., \& van Leeuwen, T. (2001). Multimodal discourse: The modes and media of contemporary communication. London: Edward Arnold.

[14] Lee, K.W. (2000). English teachers' barriers to the use of computer assisted language learning, The Internet TESL Journal. Retrieved June, 25, 2006, from http://www.4english.cn/englishstudy/xz/thesis/barrir.

[15] Maguire, L. L. (2005). Literature review: Faculty participation in online distance education: Barriers and motivators. Online Journal of Distance Learning Administration, 8 (1).

[16] Mayer, R. E. (2003). Learning and Instruction. Upper Saddle River, NJ: Prentice Hall.

[17] Mayer, R. E. (2005). Principles of multimedia learning based on social cues: personalization, voice, and image principles. In R. E. Mayer, (Ed.) The Cambridge Handbook of Multimedia Learning. New York: Cambridge University Press.

[18] Mayer, R. E., \& Chandler, P. (2001). When learning is just a click away: Does simple interaction foster deeper understanding of multimedia messages? Journal of Educational Psychology, 93, 390-397.

[19] Mayer, R. E., Sobko, K., \& Mautone, P. D. (2003). Social cues in multimedia learning: role of speakers voice. Journal of Educational Psychology, 95, 419-425.

[20] Mayer, R. E., \& Sims, V. K. (1994). For whom is a picture worth a thousand words? Extensions of a dual-coding theory of multimedia learning. Journal of Educational Psychology, 86, 389-401. 
[21] Moreno, R., \& Mayer, R. (2007). Interactive multimodal learning environments. Educational Psychology Review, 19, 309-326.

[22] Morrison, M., Sweeney, A., \& Hefferman, T. (2003). "Learning styles of on-campus and off-campus marketing students: The challenge for marketing educators", Journal of Marketing Education, 25(3), 208-217.

[23] Nunan, D. (1999). Second language teaching \& learning. Boston: Heinle \& Heinle Publishers.

[24] Pollock, E., Chandler, P., \& Sweller J. (2002). Assimilating complex information. Learning and Instruction, 12, 61-86.

[25] Salaberry, R. (1999). CALL in the year 2000: Still developing the research agenda. Language Learning and Technology, 3 (1), 104-107.

[26] Sankey, M. D. (2006). A neomillennial learning approach: Helping non-traditional learners studying at a distance. The International Journal of Education and Development using Information and Communication Technology (IJEDICT), 2 (4), $82-$ 99.

[27] Sankey, M., \& Birch, D. (2005). Researching transmodal delivery at USQ: Different horses for different courses. Paper presented at the New Researchers for New Times Conference, October 28, Queensland University of Technology, Brisbane. Australia.

[28] Scaife, M., \& Rogers, Y. (1996). External cognition: how do graphical representations work? International Journal of HumanComputer Studies, 45, 185-213.

[29] Shah, P., \& Freedman, E. G. (2003). Visuospatial cognition in electronic learning. Journal of Educational Computing Research, 29 (3), 315-24.

[30] Stoney, S., \& Oliver, R. (1999). Exploring the Nature of Self-Regulated Learning with Multimedia. Interacting Multimedia Electronic Journal of Computer enhanced Learning, 1 (2).

[31] Sweller, J. (2005). Implications of cognitive load theory for multimedia learning. In R. E. Mayer (Ed.). The Cambridge Handbook of Multimedia Learning. New York: Cambridge University Press.

[32] Taylor, R. (1980). The computer in the school: Tutor, tool, and tutee. New York: Teachers College Press.

[33] Taylor, R. \& Gitsaki, C. (2003) Teaching well and loving it. In Fotos \& Browne (Ed.), New perspectives on CALL for second language classrooms (pp. 131-147). Mahwah, NJ: Lawrence Erlbaum Associates.

[34] Tversky, B., Morrison, J. B., \& Betrancourt, M. (2002). Animation: can it facilitate? International Journal of Human Computer studies 57 (4), 247-262.

[35] Warschauer, M. (2004). Technological change and the future of CALL. In Fotos \& Browne (Ed.), New perspectives on CALL for second language classrooms (pp. 15-26). Mahwah, NJ: Lawrence Erlbaum Associates.

[36] Wellington, J. (2000). Teaching and learning Secondary Science: contemporary issues and practical approaches. London: Routledge.

[37] Warschauer, M. (2008). "Computer Assisted Language Learning: an Introduction." http://www.ict4lt.org/en/warschauer.htm. Retrieved 2008, 04-11.

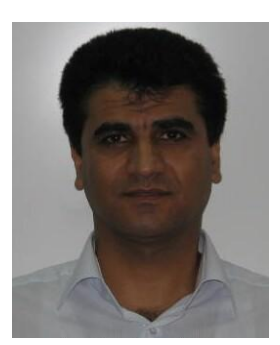

Abbas Pourhosein Gilakjani is a Ph.D. student of SLL at the Universiti Sains Malaysia, Malaysia. He is also a faculty member of English Translation Department at the Islamic Azad University of Lahijan, Iran. He has taught English courses for over 11 years at 3 open universities in Guilan, Iran.

Hairul Nizam Ismail received his Ph.D. (Educational Psychology/Instructional System Technology) from Indiana, United States of America in 1999, with specialization in the area of learning and cognition. Since that year, he has served as the faculty member at the School of Educational Studies, Universiti Sains Malaysia. For the past 11 years, he has been teaching many university courses related to educational psychology, child psychology, cognitive psychology, guidance and counseling, multiple intelligences, gifted and talented, thinking and reasoning, and psychological testing. He has written numerous journal and magazine articles, research monographs, as well as book chapters in similar topic areas. He is currently the deputy dean of graduate studies and research at the school of Educational Studies, Universiti Sains Malaysia.

Seyedeh Masoumeh Ahmadi received her B.A. degree from Islamic Azad University of Lahijan, Iran. She will start her education in M.A. in Computer Network at Universiti Sains Malaysia, Malaysia 2 months later. 